\title{
Game Analysis on the Failure of the Internal Supervision Mechanism of State-owned Enterprises
}

\author{
Feng Kong ${ }^{1}$, Yang Jiao ${ }^{1, a,{ }^{*}}$ \\ ${ }^{1}$ Department of Economics and Management, North China Electric Power University, Baoding \\ 071003, China \\ a51913584@qq.com, b175340181@163.com \\ ${ }^{*}$ Corresponding author
}

\begin{abstract}
Keywords: State-owned enterprises, Game theory, Internal supervision, Corruption.
\end{abstract}
\begin{abstract}
According to the behavior characteristics of managers of state owned enterprises, starting from the perspective of utility maximization and based on principal-agent game analysis, this paper establish a new state-owned enterprise managers corruption and internal supervisor behavior model, for the first time the internal recessive incentive effect variables is introduced in this model. This paper studies on the optimal behavior choice of state-owned enterprises managers and the internal supervisors. The existing system will induce the state-owned enterprise managers to achieve the goal of self utility maximization, and to suppress the effect of internal supervision, and connive with corruption. Finally, this paper discusses measures and suggestions about how to increase internal supervision and improve the supervision of state-owned enterprises themselves to reduce corruption of managers.
\end{abstract}

\section{Introduction}

Main part of State-owned enterprises in China as enterprises plays a vital role in China's economic development. But due to the system of special education for all State-owned enterprises, and the Government on behalf of all of us, commissioned manager to operate. However, according to the 2011-2014 Chinese entrepreneurs crime report, bribery, embezzlement, misappropriation of public funds is a state criminal charges entrepreneur frequency counts, accounted for more than $30 \%$ of the 22 charges. And in all the crimes of state-owned entrepreneurs, chairman and general manager or the legal representative accounted for nearly $50 \%$ of the total. Shuguang Wei(2004) points out that ownership is actually administered by the exercise of the functions of State-owned enterprises, and bulls management, without a specific representative shall exercise the ownership on behalf of a State function, people actually "ownerless".

In view of these phenomena, many scholars have studied. Min Wan(2004) argue that State-owned enterprise governance is mainly internal control problems. Shiqiao Zheng and Man Li(2013) argue that the failure of internal supervision is the system problem. Analysis of mechanism of supervision game is Hart and Holmstrom (1987) based on the principal-agent theory, and China's first game research in Professor Weiying Zhang (1996) the "game theory and system economics" described. For operators of behavior analysis, Feng Kong (2011)will be the operator behavior further refined into normal effort, short-term behavior, long-term behavior of multi-dimensional variables. Research on the incentive mechanism,Jun Wang (2001) thought that the present stage on managers' incentive resources can be divided into promotion incentives and revenue incentive. Jianmao Yan and Jianjun Wan (2002) proposed managers of state-owned utility function model manager expressed as control monetary income, income and reputation returns the sum of the three aspects of utility.

In this paper, the innovation lies in the state-owned enterprises and the internal supervision behavior abstraction, analysis of the causes of failure of internal supervision; using the game theory, based on real behavior, set reasonable parameters, mathematical models, evaluates behavioral inhibitions about corruption and measures to improve the supervision of impact factors, and to improve efficiency, avoid oversight failures, reducing the occurrence of managers acts of corruption. Fill the internal supervision and corrupt practices related to the game between the gaps benefit the 
future of corruption in governance.

\section{The Research on Principal-agent Model}

\section{The research model of state-owned enterprisers managers' behaviors}

According to the operator of the daily business operations conduct different functions, it can be divided into the normal behavior and corruption, $a$ and $a_{r}$ respectively. $a_{\text {is normal behavior, }}$ refers to the General daily business performance to improve operational practices which is unobservable variable. And $a_{r}$ that corruption, is refers to the operator is taken to make the enterprise performance suffered losses of self-interest, can be found in a certain probability of supervision. Operators set two acts $a$ and ${ }^{a_{r}}$ showed a linear relationship between corporate performance (Weiying Zhang, 2004):

$$
\pi=a-a_{r}+\theta
$$

Where $\theta$ is the mean of 0 and variance for normally distributed random variable $\sigma^{2}$, showing the impact of external factors on the uncertainty of corporate performance.

Assume that operator's incentive pay $S_{0}$ consists of two parts: one part is fixed salary, the other part is related to corporate earnings performance bonus (including year-end bonus, stock, options and benefits), namely:

$$
S_{0}=\alpha_{+} \beta \pi
$$

Where $\alpha$ means that managers of fixed income, $\beta$ is the coefficient of performance relative to corporate earnings.

And operator's corruption will bring the gray income, a grey income is $S_{r}$,

$$
S_{r}=K a_{r}
$$

$K$ is the coefficient of grey income.

Total revenue for the operator $S=S_{0} S_{r}$. Manager's operation will have a certain cost, cost function based operator acts as:

$$
c\left(a, a_{r}\right)=\frac{1}{2} b a^{2}+\frac{1}{2} b_{r} a_{r}^{2} ;
$$

Among them, the $b$ for normal effort cost coefficient; $b_{r}$ to corruption cost coefficient, and two kinds of behavior are independent of each other.

Internal supervision includes supervision and punishment measures, therefore, assumes that the surveillance for ${ }^{P}$, supervision, the more the greater the probability of operator's corruption was found. So you can at the same time the surveillance was defined as the probability of corruption was found, the operator once take corruption, will to $P$ the probability of being supervision institutions found that with $0 \leq P \leq 1$. If operator acts of corruption is discovered, the supervisory authority will give operators the punished $F\left(a_{r}\right)$, punished by the strength of established operators discovered is proportional to the level of corruption: 
$F\left(a_{r}\right)=f a_{r}$

Among them, $f$ is the penalty coefficient and $f \geq 0$.

For operators, maximizing its utility function as follows:

$\max C E=E(s)_{-} E\left[c\left(a, a_{r}\right)\right]_{-} P F_{-} \frac{1}{2} \rho \beta^{2} \sigma^{2}$

s.t. $\quad a, a_{r} \geq 0$;

Among them, $\rho$ is a manager of risk aversion coefficient, $\frac{1}{2} \rho \beta^{2} \sigma^{2}$ represents the operator's cost of risk.

Solution, the optimal effort level of the state-owned enterprisers' from the as follows:

$$
A^{*}=\left(a, a_{r}\right)=\left\{\frac{\beta}{b}, \max \left[\frac{K-\beta-P f}{b_{r}}, 0\right]\right\} \text {; }
$$

Visible, when $K-\beta-P f>0$, the operator will take corruption. According to the research contents of this paper assumes that the $K>\beta$ was established, otherwise no significance.

\section{Research on the Model of Internal Supervision Behavior}

Internal oversight agencies for State-owned enterprise sector, the main leadership by the operator appointed, headed by the operator directly, causing the internal oversight function is constrained by the supervisory bodies.

Assume that Internal oversight agencies pay consists of two parts: one part is fixed salary, the other part is related to corporate earnings performance bonus, namely:

$$
S_{0}^{\prime}=\alpha^{\prime}+\beta^{\prime} \pi
$$

Where $\alpha^{\prime}$ means that internal supervision of fixed income, $\beta^{\prime}$ is the coefficient of performance relative to corporate earnings.

Behavior takes supervision cost. Because of the surveillance, the greater the more difficult, supervision cost is higher. Set cost of supervision for the quadratic function:

$$
M(P)=\frac{1}{2} M P^{2} \quad ;(M \geq 0)
$$

For the head of internal supervision mechanism, internal oversight tends to be passive resistance within the enterprise, especially when monitoring for operators, there will be great resistance, easy to offend the operator. When the operator has corrupt behavior, internal oversight body to monitor the intensity of the greater degree of offending operators deeper, it will have a significant negative effect on its reputation and control over, the operator will find a way for people responsible for internal oversight recessive blow, even demoted to form supervisory barriers. It can set the internal oversight implicit incentive is negative, and the greater the supervision, the higher the implicit incentive damaged, it set up its implicit incentive function: 


$$
N(P)=-N P
$$

Among them, $N$ is expressed as the internal recessive incentive coefficient the size value associated with operator supervision barriers.

For internal supervision mechanism, to the maximum utility function:

$$
\begin{aligned}
& \max C E^{\prime}=E\left(S^{\prime}\right)-M(P)+N(P) \\
& \text { For } A^{*}=\left(a, a_{r}\right)=\left\{\frac{\beta}{b}, \max \left[\frac{K-\beta-P f}{b_{r}}, 0\right]\right\}, \text { to solve max } C E^{\prime} \text { to } \\
& P=\max \left[\frac{\beta^{\prime} f-N b_{r}}{M b_{r}}, 0\right]
\end{aligned}
$$

Can be seen from the above equation, only when $\beta^{\prime} f-N b_{r}>0$, it will be possible to take supervision supervisor.

\section{Model Analysis on the Behavior of Operators and Supervisors Game}

In the internal supervision model, managers are the consignor, commissioned by the internal supervision mechanism of supervision, namely the supervision mechanism for the agent. Operators in the enterprise has the highest form of power, right to choose $\beta^{\prime}, N, f$. To maximize the utility function:

$$
\max C E=E(S)-c\left(a, a_{r}\right)-P F-\frac{1}{2} \rho \beta^{2} \sigma^{2}
$$

Individual rationality constraint(IR):

$$
\alpha^{\prime}+\beta^{\prime} \pi-\frac{1}{2} M P_{1}^{2} \geq \omega_{2}
$$

Incentive compatibility constraint(IC): $A^{*}=\left(a, a_{r}\right)=\left\{\frac{\beta}{b}, \max \left[\frac{K-\beta-P f}{b_{r}}, 0\right]\right\}$, $P=\max \left(\frac{\beta^{\prime} f-N b_{r}}{M b_{r}}, 0\right)$

The first order conditions for the optimal solution: $\frac{\partial E}{\partial \beta^{\prime}}=0, \frac{\partial E}{\partial N}=0, \frac{\partial E}{\partial P}=0$. Solve for $f^{*}=0$, $\mathrm{P}=0, C E$ is a maximum. While the value of $\beta^{\prime}$ and $\mathrm{N}$ did not affect the optimal solution. This represents the operators for their utility to achieve maximum, will reduce the punishment until the zero, supervision and monitoring is also zero, that is, failure of internal oversight.

$$
\text { By } P=\max \left(\frac{\beta^{\prime} f-N b_{r}}{M b_{r}}, 0\right) \text {, available } \frac{\beta^{\prime} f-N b_{r}}{M b_{r}} \leq 0 \text {, so } \beta^{\prime} f-N b_{r} \leq 0 \text {. In the beginning of the }
$$

enterprise, fair operators tend to watch the other directors agreed to set $\beta^{\prime}$ supervisor with the company, and f usually given a certain symbolic value, to indicate the importance of the supervision of the operators, but of $\mathrm{f}$ values tend to be small in order to achieve their maximum utility. At a time 
when the fand $\beta$ treated as constants, and take them into (13) to give: $N^{*} \geq \frac{\beta^{\prime} f}{b_{r}}$;

Due to asymmetric information, the operator of information supervision in the weak side, often

unclear $N^{*}$ critical value, namely the size of the minimum value $\frac{\beta^{\prime} f}{b_{r}}$, thus its tend to continue to increase the size of the $\mathrm{N}$, in order to ensure the utility maximization, it will increase the recessive incentive coefficient, the $\mathrm{P}$ value faster to zero, even if the supervision malfunction, regulators do not take supervision and behavior.

\section{Implications and Discussion Based on the Internal Supervision Game Policy}

Through the model of internal supervision game theory analysis, in the current system of state-owned enterprises, because of the absence of owners, resulting in too concentrated operators power, but due to the asymmetric information, government agencies are often difficult to intervene in the operation of the internal management of enterprises. And often used his power, an operator will be on internal supervision department's supervision function "slimming", namely reduce the penalties, shielding the internal supervision mechanism, in management decisions and give its corresponding economic benefits, which to some extent improve the internal supervision mechanism of merit pay, multi-pronged and internal supervision failure.

To change the status of internal oversight failure, prompting internal oversight must play its utility from the following points:

1)The operators of power cut, reducing the constraints on the internal supervision

2)Increase the internal regulator's incentives.

Actively pursue reform of the State-owned enterprise system, the introduction of part civil capital, the implementation of mixed ownership, enhancing internal oversight.

\section{Acknowledgement}

13YJA630039 humanities and Social Science Research Foundation of Ministry education

\section{References}

[1] Yuanhang Liu. Mode selection of China's state owned assets management system. [J] Economist, 2003. 02.

[2] Shiqiao Zheng,Man Li. The "Scarecrow" Phenomenon of Supervision Institution in The State-Owned Enterprise: A Institution Coordination Theoretical Framework. [J]Journal of Beijing Normal University (Social Sciences),2013.05.

[3] Min Wan. Research on insider control of state- owned enterprises. [J] Finance and Economics, 2004.01.

[4] Yuanfang Wang,Lianfu Ma. Can the Party Organization of China s State-owned Companies Reduce Agency Cost?A Perspective Based on Insiders Control.[J] Management Review,2014.10.

[5] Rui Chang. Rethinking on the Internal Board of Supervisors System of State-owned Enterprises in China.[J] Commercial Research,2014.07.

[6] Modeling of Project Managerial Behaviors, Compensation and Enterprise 's Monitoring.[J] Chinese Journal of Management Science,2004.05.

[7] Jun Wang. The Incentives and Behavior in Dual Games.[J] Economic Research Journal,2001.08. 